\title{
Phytochemical Screening and Anticonvulsant Activity of the Residual Aqueous Fraction of Tapinanthus globiferus Growing on Ficus glums
}

\begin{abstract}
Tapinanthus globiferus (Loranthaceae) is a plant used in traditional medicine for the treatment of rheumatism, syphilis, fever and epilepsy. In this study, the acute toxicity study revealed an oral $\mathrm{LD}_{50}$ of $\geq 5000 \mathrm{mg} / \mathrm{kg}$. The anticonvulsant activity of the residual aqueous fraction was investigated at doses of 250,500 , and $1000 \mathrm{mg} /$ kg using the Pentylenetetrazole (PTZ) induced seizure and maximal electroshock seizure models in mice and chicks. In the PTZ induced seizure the fraction offered $62.5 \%$ protection against seizure and prolonged the onset of seizure from $54.23 \pm$ $6.12 \mathrm{~s}$ to $290.86 \pm 14.43 \mathrm{~s}$. The plant decreased the minimum recovery time (MRT) after hind limb tonic extension (HTLE) from $213.4 \pm 19.12 \mathrm{~s}$ to $136 \pm 16.1 \mathrm{~s}$ in the $500 \mathrm{mg} / \mathrm{kg}$ group.
\end{abstract}

The CNS depressant effect was also studied using the Diazepam induce sleep model. The fraction used dose dependently decreased the onset of diazepam induced sleep $160.03 \pm 19.24$.s to $28.00 \pm 7.18$.s, with a marked increase in duration of sleep $39.00 \pm 12.53 \mathrm{~min}$ to $198.17 \pm 27.28 \mathrm{~min}$ in the $1000 \mathrm{mg} / \mathrm{kg}$ treated group.

The data obtained from this study suggest that the residual aqueous portion of the dried whole plant of Tapinanthus globiferus may possess bioactive compounds with anticonvulsant effect.

Keywords: Tapinanthus globiferus; Pentylenetetrazole; Seizure; GABA; Protection

Received: January 16, 2016; Accepted: April 06, 2016; Published: April 12, 2016

\author{
Abubakar K ${ }^{1}$, Adebisi IM¹, \\ Ugwah-Oguejiofor JC', \\ Idris $\mathbf{G O}^{1}$, Idris $\mathrm{B}^{2}$ and \\ Mshelia $\mathrm{HE}^{3}$
}

1 Department of Pharmacology and Toxicology, Usmanu Danfodiyo University, Sokoto, Nigeria

2 Department of Pharmacology, University Sains, Malaysia

3 Department of Pharmacognosy and Ethnopharmacy, Faculty of Pharmaceutical Sciences, Usmanu Danfodiyo University, Sokoto, Nigeria

Corresponding author: Abubakar K

Đ kabirsultan2002@gmail.com

Department of Pharmacology and Toxicology, Faculty of Pharmaceutical Sciences, Usmanu Danfodiyo University, Sokoto, Nigeria

Tel: $234-8035863780$.

Citation: Abubakar K, Adebisi IM, UgwahOguejiofor JC, et al. Phytochemical Screening and Anticonvulsant Activity of the Residual Aqueous Fraction of Tapinanthus globiferus Growing on Ficus glums. Herb Med. 2016, 2:2

\section{Introduction}

Traditional systems of medicine are popular in developing countries and up to $80 \%$ of the population relies on traditional medicines or folk remedies for their primary health care need [1]. Several plants used for the treatment of epilepsy in different systems of traditional medicine have shown activity when tested in modern bioassays for the detection of anticonvulsant activity [2] and many such plants need to be scientifically investigated.

Tapinanthus globiferus is mistletoe of the family Loranthaceae. It is woody with shrubs, usually aerial hemiparasites on other seed plants, often spreading along host by runners (epicortical roots), more rarely terrestrial root-parasitic shrubs or trees, nodes not articulated, glabrous or hairy, hairs often stellate or verticillate. Tapinanthus globiferus is locally known as mistletoe (English), Kauchin (Hausa), afomo (Yoruba), and Osisi/Okwuma osa (Igbo) in Nigeria, and belongs to the family of Loranthaceae [3]. In Saudi Arabia, Tapinanthus globiferus is known as Hadhal [4].

Mistletoes of the Loranthaceae and Viscaceae, are widely used in various cultures in almost every continent to treat various ailments including hypertension, cancer, and diabetes, or used as a diuretic agent [3-5]. Other uses include cure for bone fracture and body pain [6]. T. globiferus is one of the mistletoes commonly consumed by the people of Akwa Ibom State for the treatment of hypertension, ulcers, epilepsy, diabetics, weakness of vision, and for promoting muscular relaxation before delivery [7].

Epilepsy is one of the oldest disease conditions known to mankind [8] and still the most common neurological condition affecting individuals of all ages. The incidence of epilepsy in developed countries is approximately 40 to 70 per 100000 people in the 
general population, while that of developing countries, are 80 to 140 per 100,000 [8]. The mainstay of epilepsy management is the use of antiepileptic drugs which have proved to be effective in reducing the onset and severity of attacks. Therapy is symptomatic in that available drugs inhibit seizure but neither effective prophylaxis nor cure is available [9]. The current therapy of epilepsy with modern antiepileptic drugs is associated with side effects, dose-related and chronic toxicity, as well as teratogenic effects, and approximately $30 \%$ of the patients continue to have seizures with current antiepileptic drugs therapy $[10,11]$.

Personal communication with traditional healers in Sokoto state, North western Nigeria provides enough evidence for the use of $T$. globiferus in the management of convulsive disorders. Literature search on the plant reveals the previous studies conducted which includes antibacterial effect [12] antioxidant effect [13] and antihypertensive studies via reduction of LDL and triglycerides.

\section{Methodology}

\section{Plant collection and identification}

Fresh whole plant $T$. globiferus growing on Ficus glumosa was collected from Zamfara State, Nigeria on $18^{\text {th }}$ June, 2015. The plant was identified, authenticated and given a voucher number (UDUH/ANS/0076) by Mallam Lawali Department of Biological Sciences, Usmanu Danfodiyo University Sokoto. Samples were kept for further reference. The fresh plants were then air dried at room temperature and size reduced into powder using pestle and mortar.

\section{Preparation and fractionation of the extract}

The method described by Ref. [14] modified by Ref. [15] was followed; is mentioned in Figure 1.

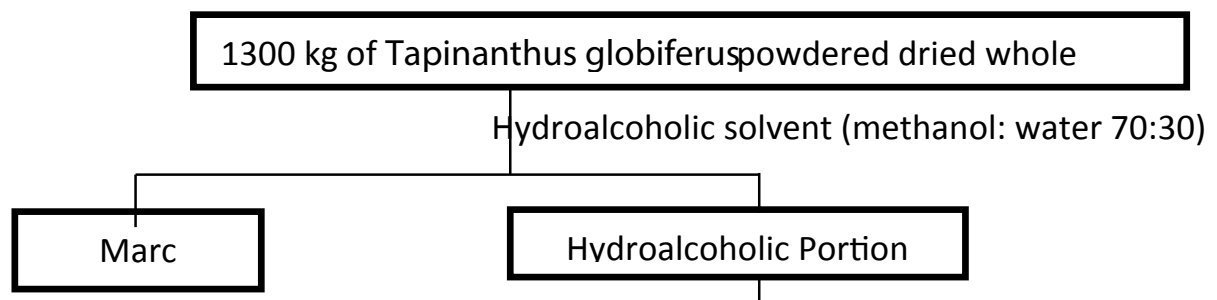

Dried extract + water $+n$ - hexane + stand over night
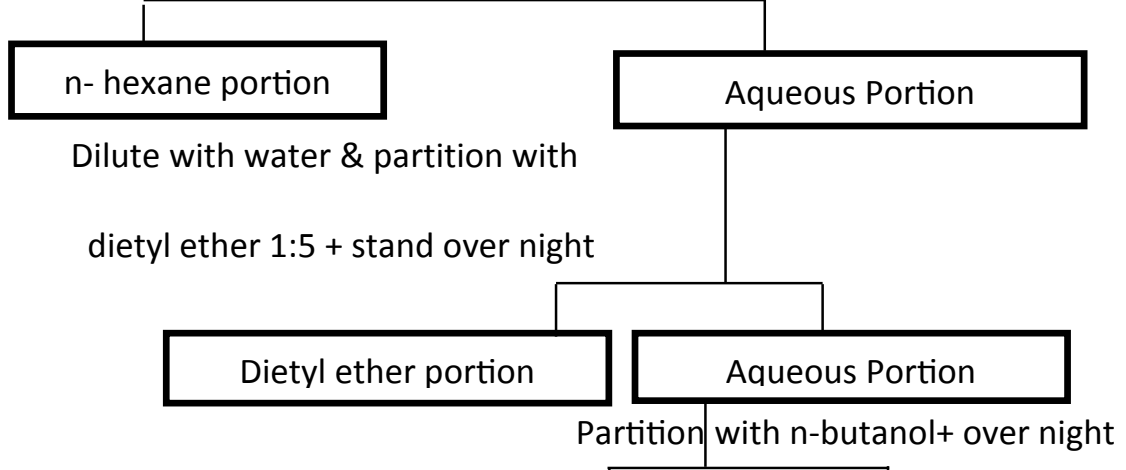

Partition with n-butanol+ over night

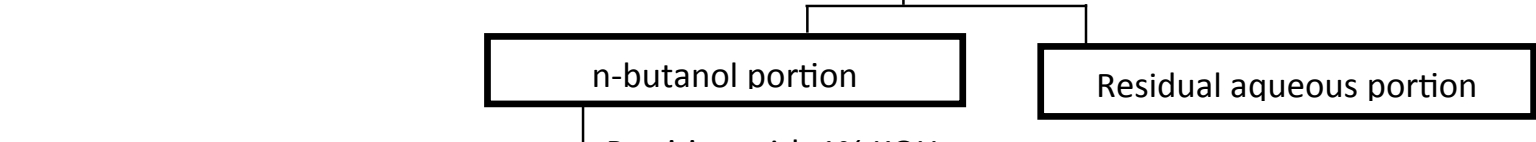

Partition with $1 \% \mathrm{KOH}$

n-Butanol (saponin)

KOH Portion

Acidified with dil. $\mathrm{HCl}$ and Partitioned

With n- Butanol Saturated with W/ater

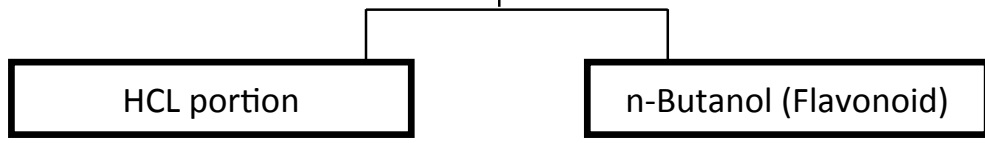

Figure 1 Schematic Chart for Fractionation of Flavonoids, Saponin from Tapinanthus globiferusi powdered whole plant, from Ref. [14]. 


\section{Experimental animals}

Mice: Adult Mice of both sexes weighing between $24 \mathrm{~g}$ and 32 $g$ were obtained from the Animal house facility of the of Faculty Pharmaceutical sciences, Ahmadu Bello University Zaria. The animals were maintained in a well - ventilated room, under ambient laboratory conditions of temperature and humidity and were fed on commercial feed and water except when fasting was required in the course of study. All experiment protocols were approved by the University animal ethics committee.

Chicks: Two day old chicks were bought from Ojuanu Agricultural enterprise No. 32 Sultan Atiku road Sokoto, Sokoto State prior to the experiment and were allowed to acclimatize to the laboratory environment before the practical.

\section{Phytochemical screening}

The dried residual aqueous extract of the whole plant of Tapinanthus globiferus was subjected to phytochemical screening tests for the detection of various constituents [16].

\section{Acute toxicity studies}

Acute toxicity study was determined using Ref. [17] via oral route in mice and chicks.

Diazepam-induced sleep in two day old chicks: The chicks were divided into four groups of ten chicks each. Group 1-3 received $250,500,1000 \mathrm{mg} / \mathrm{kg}$ of $T$. globiferus residual aqueous fraction respectively via intra-peritoneal route; group 4 received distilled water which served as control, in equivalent volume of the extract. Thirty minutes post administration all the groups were administered diazepam $10 \mathrm{mg} / \mathrm{kg}$ i.p. The onset and duration of sleep was observed and recorded with the chicks placed in individual cages. Loss of righting reflex [18] touching the floor with the beak and leaning on the wall of the cage for support was considered as the criterion for sleep, while the interval between the loss and the recovery of straightening was regarded as the duration of sleep [19].

Pentylenetetrazole (Ptz) induced seizure in mice: The method described by Ref. [19] was employed for this study. 40 mice were divided into five groups each containing 8 mice each. The first group received diazepam $30 \mathrm{mg} / \mathrm{kg}$ body weight i.p, groups $2-5$ received $250,500,1000 \mathrm{mg} / \mathrm{kg}$ body weight respectively of the extract orally, $0.2 \mathrm{mls}$ distilled water i.p was given to the fifth group which served as the negative control. Clonic seizures were induced in the mice by the i.p. injection of $70 \mathrm{mg} / \mathrm{kg}$ of PTZ to all the groups after 1 hour. The onset of seizures in non-protected mice was also recorded.

Maximum electroshock test (Mest): The method described by Ref. $[20,21]$ was used in this study. Two day old cockerels were used; they were randomly divided into five groups of ten animals each. The first group was administered distilled water $10 \mathrm{ml} / \mathrm{kg}$ i.p, while the second, third and fourth group received 250,500 , $1000 \mathrm{mg} / \mathrm{kg}$ ip of the extract respectively. The fifth group received phenytoin $20 \mathrm{mg} / \mathrm{kg}$ i.p, thirty minutes after drug treatment maximum electroshock was administered to the chicks to induce seizure in the chicks using Ugo Basile electroconvulsive machine (model 57800-001) with corneal electrode placed on the upper eyelids of the chicks after being moistened with normal saline.
The shock duration, frequency and pulse width were set and maintained at $0.6 \mathrm{~s}, 100$ pulse/second and $0.6 \mathrm{~m} / \mathrm{s}$ respectively. $A$ current of $80 \mathrm{~mA}$ was used throughout. Seizures were manifested as hind limb tonic extension (HLTE) in the chicks [22]. The ability of the extract to prevent this feature or shorten the recovery from HLTE was considered an indication of anticonvulsant activity $[21,22]$.

\section{Results}

\section{Percentage yield}

Percentage yield $=\frac{\text { weight of extract }}{\text { weight of powdered drug }} X 100$

$77 / 1300 \times 100 \%=5.9 \% \mathrm{w} / \mathrm{w}$

\section{Acute toxicity studies}

Acute toxicity studies: The oral $\mathrm{LD}_{50}$ of the extract was found to be greater than $5000 \mathrm{mg} / \mathrm{kg}$ in both chicks and mice. From the results in Table 1, the residual aqueous fraction of $T$. globiferus contains carbohydrates, tannins, saponins, flavonoid, proteins, glycosides and steroids with the absence of anthraquinones and triterpenes.

\section{Effect of $T$. globiferus on PTZ induced seizure}

The result on Table 2; indicated that the residual aqueous portion of T. $g 250$ and $500 \mathrm{mg} / \mathrm{kg}$ significantly prolong the latency to PTZ induced seizure. Also $1000 \mathrm{mg} / \mathrm{kg}$ of the extract protected $62.5 \%$ of the mice against PTZ seizure. The anticonvulsant drug diazepam $5 \mathrm{mg} / \mathrm{kg}$ provided $100 \%$ protection against seizure and mortality.

\section{Effect of T. globiferus residual aqueous fraction on maximal electroshock seizure}

The result of the MES test indicated that the extract offered no protection against seizure and there was $100 \%$ death of all the chicks. Though there was a significant decrease in the mean recovery time, none of the chicks survived beyond 60 minutes after induction of seizure (Table $\mathbf{3}$ ).

Table 1 Phytochemical composition of the Residual aqueous fraction of T. globiferus.

\begin{tabular}{|c|c|}
\hline Constituents & Result \\
\hline Carbohydrates & + \\
\hline Tannins & + \\
\hline Alkaloids & + \\
\hline Saponins & + \\
\hline Flavonoid & - \\
\hline Anthraquinones & + \\
\hline Proteins & + \\
\hline Glycosides & + \\
\hline Steroids & - \\
\hline Triterpenes & + \\
\hline
\end{tabular}

Where, +: Present; -: Absent 


\section{Discussion}

The phytochemical screening of the Tapinanthus globiferus revealed the presence of constituents such as Saponins, Tannins, Glycosides, Protein, Steroids and Flavonoids. Pharmacological effects of plant phytochemicals have been previously documented. Alkaloids have been reported to function as amoebicides, expectorant, anaesthetic, analgesic and antihelminthic [23]. Saponins have been said to be beneficial in lowering blood cholesterol $[7,24]$. Flavonoids also referred to as nature's biological response modifiers, have been found to have the ability to modify the body's reaction to allergens, viruses and carcinogens [25]. Anticonvulsant effect of saponins and flavonoids has been reported by Ref. [26-29].

Acute toxicity studies of the plant gave an $L_{50}$ that can be classified as non- toxic. According to Dietrich Lorke $1 \mathrm{mg} / \mathrm{kg}$ is considered highly toxic, $10 \mathrm{mg}$ as toxic, $100 \mathrm{mg} / \mathrm{kg}$ as moderately toxic, $1000 \mathrm{mg} / \mathrm{kg}$ as slightly toxic and nontoxic above $5000 \mathrm{mg} /$ $\mathrm{kg}$ [17]. The highest dose used in this study was $1000 \mathrm{mg}$ which represented $20 \%$ of the highest dose tolerated by the animals.

The potentiating of the sleep time suggests the presence of sedative properties in the extract of the plant [30,31] (Figure 2). The sedative properties could be related to the presence of some components in the fraction activating the benzodiazepine, barbiturate and/or GABA receptors in the GABAA receptor complex [32]. Diazepam act by binding to the GABAA receptor complex. Diazepam potentiates GABA-mediated inhibition via increase in the affinity of this inhibitory neurotransmitter to its recognition sites within the GABAA receptor complex, by increasing the opening frequency of the chloride ion channel which leads to the enhancement of influx of chloride anions into the neuron and subsequent hyperpolarisation [33].

Tapinanthus globiferus residual aqueous fraction at a dose of $250-500 \mathrm{mg} / \mathrm{kg}$ prolonged the onset of seizure. At a dose of 1000 $\mathrm{mg} / \mathrm{kg}$ it offered $62.5 \%$ protection against myoclonic seizures induced by PTZ. The anticonvulsant drug (diazepam $5 \mathrm{mg} / \mathrm{kg}$ ) prevented the mice against seizure. The PTZ test is known to identify anticonvulsant drugs effective against myoclonic and absence seizure and may elicit seizures by inhibiting gabaergic mechanisms [34]. Standard antiepileptic drugs, Diazepam and Phenobarbiton are believed to produce their effects by enhancing GABA mediated inhibition in the brain [32]. From this study it can be said that the plant may be of benefit in human myoclonic and absence seizure.

The MES test is the most frequently used animal model for identification of anticonvulsant activity of drugs for the generalized tonic-clonic seizures "grand mal" [35]. Electroshock seizures are characterized by tonic extension of the hind limb (HLTE), [15]. Antiepileptic drugs that antagonize MES-induced tonic extension are known to act by blocking seizure spread [36]. Moreover, drugs that inhibit voltage-dependent $\mathrm{Na}^{+}$channels, such as phenytoin can prevent MES-induced tonic extension [36]. In this study maximal electroshock produced seizures in all the animals used but the extract decreased the duration of tonic clonic seizure. The ability of $T$. globiferus to decrease the duration of seizure in the MES test is indicative of its activity against generalized tonic clonic seizures $[37,38]$.

The result of this study suggest that the residual aqueous fraction of Tapinanthus globiferus growing on Ficus glumosa possess bioactive principles with CNS depressant activity and; significant anticonvulsant activity in mice and chick; this supports the Ethno medical use of the plant in the treatment of epilepsy.

\section{Recommendations}

Further studies should be carried on the plant to isolate the compound(s) responsible for the anticonvulsant activity. Studies should also be carried out using other models of epilepsy to identify the possible mechanism of action. Pharmacological screening should be done generally on Mistletoes because they are used traditionally for treatment of many disease conditions.

Table 2 Result of the effect of the residual aqueous fraction of T. globiferus against PTZ induced seizure.

\begin{tabular}{|c|c|c|c|c|}
\hline Treatment $(\mathbf{m g} / \mathbf{k g})$ & Onset of seizure (sec) & Quantal protection & \% protection & \% mortality \\
\hline D/W & $54.23 \pm 6.12$ & $0 / 8$ & 0 & 0 \\
\hline 250 & $280.11 \pm 12.09 *$ & $0 / 8$ & 25 & 100 \\
\hline 500 & $290.86 \pm 14.43^{*}$ & $2 / 8$ & 62.5 & 0 \\
\hline 1000 & $62.33 \pm 6.60$ & $5 / 8$ & 100 & 0 \\
\hline Diazepam & 0 & $8 / 8$ & & 0 \\
\hline
\end{tabular}

Values are expressed as Mean $\pm S E M, n=8$, *Statistically significant $P<0.05$ as compared with the negative control (one way ANOVA followed by Dunnett's test).

Table 3 Result of the effect of T. globiferus on maximal electroshocks seizure.

\begin{tabular}{|c|c|c|c|c|}
\hline Treatment $(\mathrm{mg} / \mathrm{kg})$ & Mean recovery time (sec) & Quantal protection & \% protection & \% Mortality \\
\hline D/W 10 & $213.4 \pm 19.1$ & $0 / 8$ & 0 & 0 \\
\hline T. g 250 & $139 \pm 16.9^{* *}$ & $0 / 8$ & 0 & 0 \\
\hline T. g 500 & $136 \pm 16.1^{* *}$ & $0 / 8$ & 0 & 0 \\
\hline T. 1000 & $102 \pm 13.7^{* *}$ & $0 / 8$ & 0 & 0 \\
\hline Ph 20 & $68.5 \pm 3.4^{* *}$ & $8 / 8$ & 100 & 0 \\
\hline
\end{tabular}

Values are expressed as Mean $\pm \mathrm{SEM}, \mathrm{n}=10$, *Statistically significant $\mathrm{p}<0.05,{ }^{*} \mathrm{p}<0.01,{ }^{* * *} \mathrm{p}<0.001$ as compared with the negative control. $\mathrm{D} /$ $\mathrm{W}=$ Distilled water, $\mathrm{pH}=$ Phenytoin. 


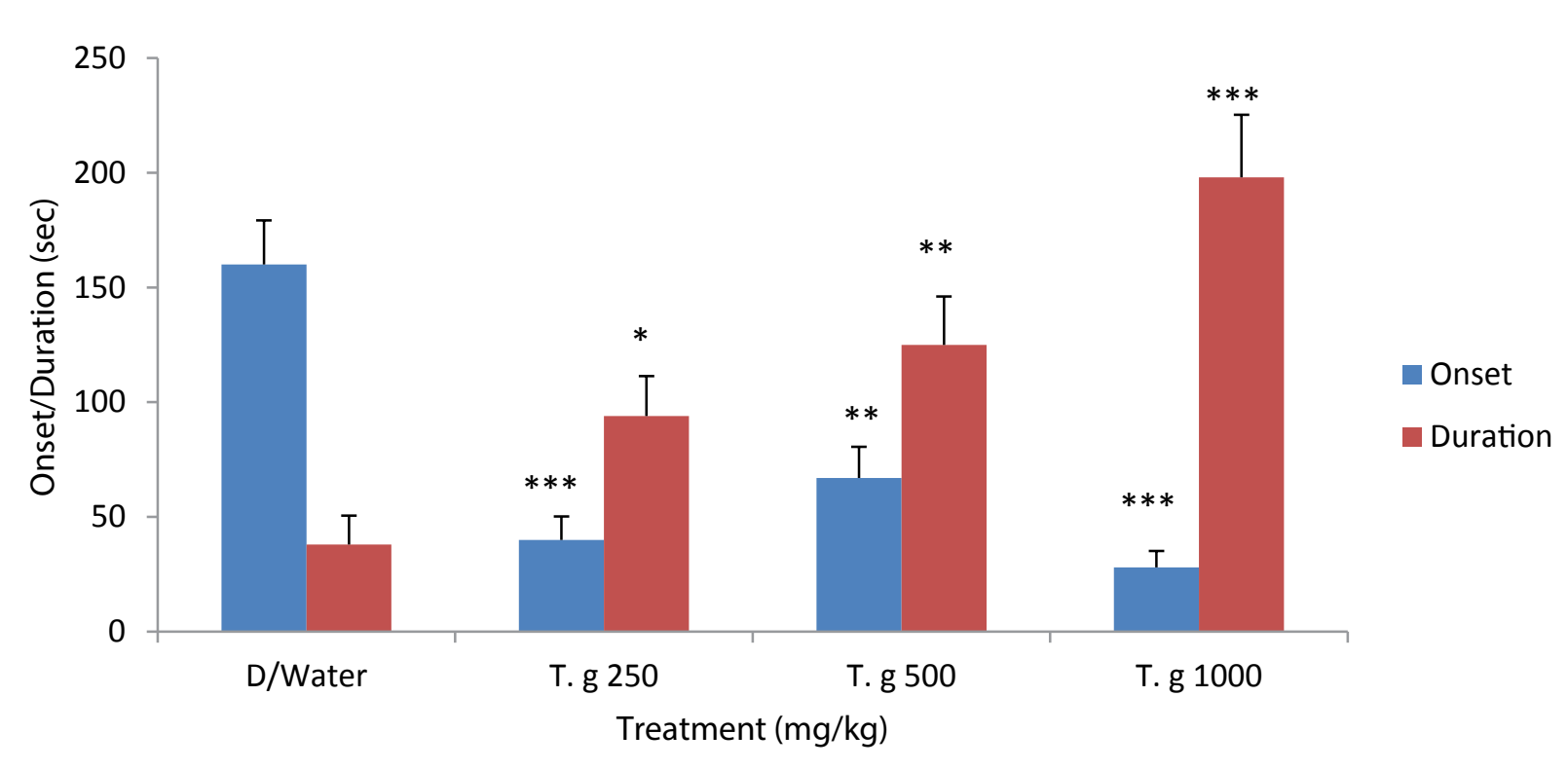

Figure 2 Sleep potentiating properties of T. globiferus in diazepam induced sleep model; Results are expressed as mean \pm SEM, $n=8,{ }^{*}=p<0.05$ (one way ANOVA followed by Dunnett's test). 


\section{References}

1 Akerele O (1988) Medicinal plants and primary health care: an agenda for action. Fitoterapia LIX pp: 355-363.

2 Raza M, Shaheen F, Choudhary MI, Rah-man A, Sombati S, et al. (2003) Anticonvulsanteffect of FS-1 subfraction isolated from roots of Delphinim denudatum onhippocampal pyramidal neurons. Phytother Res 17: 38-43.

3 Burkill HM (2000) Useful Plants of West Tropical Africa, 2nd edition Royal Botanic Gardens, New England 5: 548-560

4 Sher H, Alyemeni MN (2011) Pharmaceutically important plants used in traditional system of Arab medicine for the treatment of livestock ailments in the kingdom of Saudi Arabia. African Journal of Biotechnology 10: 9153-9159.

5 Jadhav N, Patil CR, Chaudhari KB, Wagh JP, Surana SJ, et al. (2010) Diuretic and natriuretic activity of two mistletoes species in rats. Phcog Research 2: 50-57.

6 Ken'ichi M, Kazuhiro N, Norimasa N, Dawa D, Laximi T, et al. (2006) Report of investigation for Wild Edible Plants and their Traditional Knowledge in Bhutan. J Faculty Agric 42: 37-47.

7 Bassey ME, Etuk EUI, Bala D, Ajibesin KK, Nworu F (2004) Journal of Environmental Design, pp: 141

8 Epilepsy: Aetiogy (2001) Epidemiology and prognosis WHO.

9 McNamara JO (2001) Drugs effective in the therapy of the epilepsies. In Hardman JG, Limbird LE, Goodman GA, 10th edn. Goodman and Gilman's the pharmacological basis of therapeutics.

10 Mattson RH (1992) Drug treatment of partial epilepsy. Adv Neurol 57: $643-650$

11 SamrJn EB, Duijn CM, Koch S, Hiidesmaa VK, Klepel H, et al. (1997) Maternal use of antiepileptic drugs and the risk of major congenital malformations: A joint European prospective study of human teratogenesis associated with material epilepsy. Epilepsia, p: 981.

12 Ndukwe IG, Amupitan JO, Ashonibare OE (2001) Phytochemical analysis and antimicrobial activity screening of the crude extracts from the aerial parts of Tapinanthus globiferus. Nig J Chem Res 6 : 43-46.

13 Cook JA, Van der Jagt DJ, Dasgupta A, Mounkaila G, Glew RS, et al. (1998) Use of the Trolox assay to estimate the antioxidant content of seventeen edible wild plants of Niger. Life Sci 63: 105-110.

14 Woo WS, Shin KH, Kang SS (1980) Chemistry and Pharmacology of Flavone -C- Glycoside from ziziphus seeds. Kor J of Pharmacog 11: 141-148.

15 Abubakar K, Abdulkadir R, Etuk EU, Famoriyo PO (2013) Evaluation of the antidiarrhoeal effect of Vitellaria paradoxa Gaertn $F$ (Sapotaceae) stem bark extract. Adv Life Sci Technol 15: 1-5.

16 Sofowora A (1993) Screening plants for bioactive agents. In medicinal plants and traditional in Africa. Spectrum Books Ltd Ibadan pp: 134-156.

17 Lorke D (1983) A new Approach to Practical Acute Toxicity Testing. Archives of Toxicology Journal 54: 275-287.

18 Fujimori $\mathrm{H}$ (1965) Potentiation of barbital hypnosis as an evaluation method of central nervous system depressant. Psychopharmacol 7 : 374-378.

19 Ngo Bum E, Schmutz M, Meyer C, Rakotonirina A, Bopelet $M$, et al. (2001) Anticonvulsant properties of the methanolic extract of Cyperus articulates (Cyperaceae). J Ethnopharmacol 76: 145-150.
20 Swinyard EA, Kupferberg HJ (1985) Antiepileptic drugs; detection, quantification and evaluation. Federetion Proceedings 44: 39-43.

21 Sayya M, Saroukhani G, Peirovi A, Kamalinejad M (2002) Analgesic and anti-inflammatory activity of the leaf essential oil of Lauraus nobilis Linn. Phytotherapy Research 17: 733-736.

22 Swinyard EA (1969) Laboratory evaluation of antiepileptic drugs. Review of laboratory methods. Epilepsia 10: 107-119.

23 Fabricant DS, Farnsworth NR (2001) Environment Health Perspective, York: McGraw-Hill Companies Inc 109: 521-548.

24 Price KR, Johnson IT, Fenwick GR (1987) Critical Reviews in Food Science and Nutrition, 26;27. related triterpenoid compounds. Journal of Korean medical sciences 16: S28-37.

25 Yamamoto Y, Gaynor RB (2006) Journal of Clinical Investigation 107: 135.

26 Shibata S (2001) Chemistry and Cancer preventing Activities of Ginseng saponins and some related triterpenoid compounds. Journal of Korean medical sciences 16: S28-37.

27 Kavvadias D, Sand P, Youdim KA, Qaiser MZ, Rice-Evans C, et al. (2004) The flavone hispidulin, a benzodiazepine receptor ligand 441 with positive allosteric properties traverses the blood brain barrier and exhibit anticonvulsant effects. British Journal of Pharmacology 142: 811-820.

28 Chindo BA, Anuka JA, Lees G, Yaro AH, Adamu SS, et al. (2008) Psycho pharmacological properties of the saponin fraction of Ficus platyphylla stem bark. International Journal of Biological and Chemical Sciences 2: 239-248.

29 Chindo BA, Anuka JA, McNeil L, Yaro AH, Adamu SS, et al. (2009) Anticonvulsant properties of saponins from Ficus platyphylla stem bark. Brain Research Bulletin 78: 276-282.

30 Rakotonirina SV, Ngo bum E, Rakotonirina A, Bopelet $M$ (2001) Sedative properties of the decoction of the rhizomes of Cyperusarticulatus. Fitoterapia 72: 22-29.

31 Ngo bum, Taiwe E, Moto FC, Ngoupaye, GT, Nkantchoua GCN (2009) Anticonvulsant, anxiolytic and sedative properties of the roots of Nauclea latifolia Smith in mice. Epilepsy Behav 15: 434-440.

32 Rang HP, Dale MM, Ritter JM, Flower RJ (2007) Rang and Dales Pharmacology. Churchill and Livingstone Elsevier.

33 Czapinski P, Blaszczyk B, Czuczwar SJ (2005) Mechanisms of Action of Antiepileptic Drugs. Current Topics in Medicinal Chemistry 5: 3-143.

34 De Sarro G, Ferreri G, Gareri P, Russo E, De Sarro A, et al. (2003) Comparative anticonvulsant activity of some 2,3-benzodiazepine derivatives in rodents. Pharmacol Biochem Behav 74: 595-602.

35 Löscher W, Schmidt D (1988) Which animal model should be used in the search for new antiepileptic drugs? A proposal based on experimental and clinical considerations. Epilepsy Res 2: 145-181.

36 Rogawski MA, Porter RJ (1990) Antiepileptic drugs: Pharmacological mechanisms and clinical efficacy with consideration of promising developmental stage compounds. Pharmacol Rev 42: 223-286.

37 De Deyn PP, D'Hoope R, Marescau B, Pei YQ (1992) Chemical model for epilepsy with some references to their applicability in the development of anticonvulsants. Epilepsy Research 12: 87-110.

38 White HS, Wolf HH, Woodhead JH, Kupferberg HJ (1998) The National Institute of Health anticonvulsant drug development program: Screening for efficacy. In: Antiepileptic Drug Development: Advances in Neurology, Lippincott-Raven Publishers: Philadelphia, USA 76: 29-39. 